\title{
Seroprevalence of Toxoplasma gondii and associated risk factors among pregnant women in Jimma town, Southwestern Ethiopia
}

\author{
Endalew Zemene ${ }^{1 *}$, Delenasaw Yewhalaw² ${ }^{2}$ Solomon Abera', Tariku Belay ${ }^{1}$, Abdi Samuel $^{3}$ and Ahmed Zeynudin ${ }^{1}$
}

\begin{abstract}
Background: Toxoplasmosis is a common parasitic infection caused by an obligate intracellular protozoan, Toxoplasma gondii. If primary toxoplasmosis occurs during pregnancy about one third of the cases could lead to congenital toxoplasmosis, with subsequent pathological effects. This study aimed at determining the seroprevalence of T. gondii among pregnant women in Jimma town, Southwest Ethiopia.

Methods: A community based cross-sectional study was conducted to assess the seroprevalence and associated factors in pregnant women from August to September, 2011. A total of 201 study participants were included in this study. Data on socio-demographic and predisposing factors were collected from each study participant. Moreover, venous blood specimens were collected following Standard Operating Procedures. All the collected specimens were tested for IgM and IgG anti-T. gondii antibodies by enzyme-linked immunosorbent assay (ELISA).

Results: The overall seroprevalence of T. gondii in the study area was $83.6 \%$. One hundred and sixty three (81.1\%) of the pregnant women were $\lg \mathrm{G}$ seropositive, five (2.5\%) were $\operatorname{lgM}$ seropositive. Three of the 5 pregnant women were positive for both IgG and IgM. Presence of domestic cat at home showed significant association with anti- $T$. gondii seropositivity ( $\mathrm{OR}=5.82,95 \% \mathrm{Cl}: 1.61-20.99 ; \mathrm{p}<0.05)$.

Conclusion: The seroprevalence of T. gondii antibodies was high among the pregnant women. Pregnant women having domestic cat at their home were at higher risk of $T$. gondii infection. Hence, health education and awareness on the disease and its transmission to women of reproductive age group in general and pregnant women in particular should be created during antenatal follow up to reduce the risk of T. gondii infection in pregnant women.
\end{abstract}

Keywords: Seroprevalence, Pregnant women, T. gondii, Ethiopia

\section{Background}

Toxoplasmosis is a disease caused by an obligate intracellular protozoan parasite Toxoplasma gondii. It is commonly transmitted to humans by accidental ingestion of oocyst stage of the parasite after cleaning an infected cat's litter box. Other routes of transmission include accidental ingestion of the parasite in contaminated soil and drinking water, and consumption of infected raw meat. It can also be transmitted congenitally during pregnancy [1].

\footnotetext{
* Correspondence: endalew.zemene@ju.edu.et

'Department of Medical Laboratory Sciences and Pathology, College of Public Health and Medical Sciences, Jimma University, Jimma, Ethiopia Full list of author information is available at the end of the article
}

Generally, it is estimated that about one third of the World's population is infected with T. gondii. High prevalence of the infection have been reported among pregnant women and women of childbearing age from different foci in Latin America, parts of Eastern/Central Europe, the Middle East, parts of south-east Asia and Africa [2]. However, the prevalence of T. gondii in pregnant women in China was less than 10\% [3]. In Africa, overall seroprevalence rate as high as $92.5 \%$ has been reported [4]. Most pregnant women infected with T. gondii are chronically infected while few acquire the infection during pregnancy [5]. Pregnant women with acute infection during pregnancy are at risk of congenitally transmitting the infection to the fetus.

\section{Biomed Central}

(c) 2012 Zemene et al.; licensee BioMed Central Ltd. This is an Open Access article distributed under the terms of the Creative Commons Attribution License (http://creativecommons.org/licenses/by/2.0), which permits unrestricted use, distribution, and reproduction in any medium, provided the original work is properly cited. 
Congenital transmission as a result of primary infection during pregnancy is higher if the infection is acquired during the third trimester of pregnancy and is lower if the infection occurs during the first trimester. But, congenital infection occurring during the first trimester may result in a higher risk of tragic outcomes, which may include abortion [6], than the infection at the third trimester [7].

In spite of presence of stray cats and suitable climatic conditions favoring survival of the parasite in the study area, to our knowledge, there is no documented data on the epidemiology of Toxoplasma infection in the study area. Absence of documented data initiated us to undertake this study for evidence-based decision to support prevention and control of the disease. Besides this, serological screening of pregnant women for $T$. gondii is not practiced yet as an antenatal examination in health facilities in Ethiopia. Therefore, this study is aimed at determining seroprevalence of $T$. gondii and assessing associated factors among pregnant women in Jimma town.

\section{Methods}

\section{Study area}

The study was conducted in Jimma town, located $350 \mathrm{Kms}$ southwest of the capital Addis Ababa. The town is divided into 13 kebeles (smallest administrative units in Ethiopia). According to the 2007 Central Statistical Agency census report [8] the projected total population of the town is 134,040 , females constituting $49.7 \%$. The town is generally characterized by warm climate.

\section{Study design and sample size determination}

A community based cross-sectional study was conducted from August to September 2011. The sample size was calculated using Epi Info (CDC, Atlanta, U.S.A., 2005) 6.04 statistical package. Sample size was calculated assuming the expected frequency of disease among unexposed group is 60\% [9] and among population exposed 92.5\% [4], 95\% confidence level and 80\% power, which gave us sample size of 64 . After multiplying it by three for design effect and adding 10\% for the anticipated non-response rate, the final sample size was calculated to be 211 .

A multistage sampling technique was employed to select study participants. First, five kebeles were selected from the 13 kebeles of the town by lottery method. Then, the calculated sample size was allocated to the five selected kebeles proportional to the total number of pregnant women residing in each kebele. Finally, pregnant women in any of the three trimesters were selected by systematic sampling. Trained nurses, conversant of the local language interviewed the study participants about socio-demographic characteristics and associated predisposing factors using pretested semi-structured questionnaire. The questionnaire was first prepared in English (Additional file 1) and then translated to the local language (Afan Oromo). Moreover, venous blood specimens were collected from each study participant by experienced laboratory technologists following standard operating procedures.

\section{Specimen collection and laboratory processing}

About $2 \mathrm{ml}$ of venous blood was collected by needle and syringe technique aseptically from each of the study participants. The blood samples were then transported to parasitology laboratory of the department of Medical Laboratory Sciences and Pathology. Then serum was separated from the whole blood by centrifugation at 3000 rpm for $5 \mathrm{~min}$. Separated serum was labeled and kept at $-20^{\circ} \mathrm{C}$ until use. Finally, it was tested for anti-T. gondii IgG and IgM antibodies using ELISA test kit (Human Gesellschaft für Biochemica und Diagnostica $\mathrm{mbH}$, Germany) following the manufacturer's instruction.

\section{Data analysis}

Data collected were checked for completeness and consistency and the data were entered in to a computer and analyzed using SPSS version 16.0 software package. Bivariate and multivariate logistic regressions were used for the analysis. P-values less than 0.05 were considered statistically significant in the analysis.

\section{Ethical considerations}

Ethical clearance was obtained from Jimma University Research and Ethics Review Committee and permission was obtained from Jimma Zone Health Bureau. Informed written consent was sought from each pregnant woman prior to involvement in the study. Information collected from each study participant was kept confidential and venous blood specimens collected were preserved anonymously.

\section{Results}

\section{Socio-demographic characteristics}

A total of 201 pregnant women of age ranging 17 to 35 years (mean 23.64 years) had participated in this study. About half (48.3\%) of the study participants were in the age range of 20-24 years. Majority of them $(80.6 \%)$ were house wives in occupation. Nearly a quarter of the pregnant women were illiterate (who were unable to read and write) (Table 1). Eighty three (41.3\%) of the pregnant women were primigravidae, and the remaining were multigravidae.

\section{Seroprevalence of $T$. gondii}

The overall seroprevalence of $T$. gondii among the pregnant women was $83.6 \%$. One hundred and sixty three 
Table 1 Distribution of $T$. gondii along with demographic characteristics of the pregnant women $(n=201)$, Jimma town, 2011

\begin{tabular}{|c|c|c|c|}
\hline \multirow{2}{*}{$\begin{array}{l}\text { Demographic } \\
\text { characteristics }\end{array}$} & \multicolumn{2}{|c|}{ Seroprevalence } & \multirow{2}{*}{$\begin{array}{l}\text { Total } \\
\text { n (\%) }\end{array}$} \\
\hline & $\begin{array}{c}\text { Positive } \\
\text { n (\%) }\end{array}$ & $\begin{array}{c}\text { Negative } \\
\text { n (\%) }\end{array}$ & \\
\hline \multicolumn{4}{|l|}{ Age group (years) } \\
\hline $15-19$ & $16(64.0)$ & $9(36.0)$ & $25(12.4)$ \\
\hline $20-24$ & $81(83.5)$ & $16(16.5)$ & $97(48.3)$ \\
\hline $25-29$ & $55(88.7)$ & $7(11.3)$ & $62(30.8)$ \\
\hline $30-35$ & $16(94.1)$ & $1(5.9)$ & $17(8.5)$ \\
\hline \multicolumn{4}{|l|}{ Occupation } \\
\hline Housewives & $134(82.7)$ & $28(17.3)$ & $162(80.6)$ \\
\hline Merchants & $14(82.4)$ & $3(17.6)$ & $17(8.5)$ \\
\hline House maids & $6(75)$ & $2(25)$ & $8(4.0)$ \\
\hline Daily laborers & $7(100)$ & 0 & $7(3.5)$ \\
\hline Others & $7(100)$ & 0 & $7(3.5)$ \\
\hline \multicolumn{4}{|l|}{ Level of education } \\
\hline Illiterate & $38(77.6)$ & $11(22.4)$ & $49(24.4)$ \\
\hline Read and write only & $13(86.7)$ & $2(13.3)$ & $15(7.5)$ \\
\hline Grade 1-4 & $32(82.1)$ & $7(17.9)$ & $39(19.4)$ \\
\hline Grade 5-8 & $44(86.3)$ & $7(13.7)$ & $51(25.4)$ \\
\hline Grade 9-12 & $37(90.2)$ & $4(9.8)$ & $41(20.4)$ \\
\hline $12+$ & $4(66.7)$ & $2(33.3)$ & $6(3.0)$ \\
\hline \multicolumn{4}{|l|}{ Trimester of pregnancy } \\
\hline $1^{\text {st }}$ trimester & $23(79.3)$ & $6(20.7)$ & $29(14.4)$ \\
\hline $2^{\text {nd }}$ trimester & $86(82.7)$ & $18(17.3)$ & $104(51.7)$ \\
\hline $3^{\text {rd }}$ trimester & 59 (86.8) & $9(13.2)$ & $68(33.8)$ \\
\hline
\end{tabular}

(81.1\%) of them were IgG seropositive, indicating either past infection or acquired immunity. Five $(2.5 \%)$ of them were IgM seropositive, three of the five were positive for both IgM and IgG.

\section{Factors associated with $T$. gondii}

Of the total 201 study participants, about $8.5 \%$ were within age range of 30-35 years. Amongst these age groups, $94.1 \%$ of them were positive for anti-T. gondii antibody. Anti-Toxoplasma seroprevalence of the pregnant women showed an increasing pattern of seropositivity with increasing age group. After adjusting for other factors, age showed significant association $(\mathrm{p}=$ 0.03 ) with $T$. gondii infection (Table 2).

With regard to the association of seroprevalence with educational background, $49(24.4 \%)$ of the pregnant women were illiterate, of which $77.6 \%$ were seropositive. There was no significant difference $(p=0.19)$ in seropositivity rate between the illiterate and literate study participants. Regarding occupation of the participants, $80.6 \%$ of them were housewives. Of these, about $82.7 \%$ were seropositive for $T$. gondii. There was no significant difference $(\mathrm{p}=0.5)$ in Toxoplasma seropositivity among individuals with different occupation. All the pregnant women responded had no history of blood transfusion. About $51.7 \%$ of the pregnant women were within their second trimester gestational period. The study showed that an increase in trimester had a corresponding increase with distribution of the infection.

Domestic cats were recorded from fifty nine (29.4\%) of the study households, of which $95 \%$ were positive for anti-T. gondii antibody. Participants having domestic cat at home showed significant association $(\mathrm{OR}=5.82,95 \%$ CI: 1.61-20.99, $\mathrm{p}<0.05)$ with $T$. gondii antibodies (Table 2). Over $50 \%$ of the study participants reported to have a habit of eating raw meat, of which, $82.9 \%$ were T. gondii seropositive. However, there was no significant association $(\mathrm{p}=0.7)$ between habit of eating raw meat and T. gondii seropositivity. Overall, $87.6 \%$ of the study participants reported to use pipe water as a source of drinking water. Seroprevalence among those who reported to use pipe water was $84.1 \%$. Source of drinking water did not show significant association $(\mathrm{p}=0.6)$ with Toxoplasma seropositivity (Table 2). Majority of the pregnant women $(73.6 \%)$ had reported to have a history of engagement in farming activities, which could indicate frequent contact with soil. Of these, 121 (81.8\%) of them were seropositive. Having a history of contact with soil did not demonstrate significant association $(\mathrm{P}=0.2)$ with Toxoplasma seropositivity.

\section{Discussion}

This study showed an overall $83.6 \%$ seroprevalence of anti- $T$. gondii antibody among pregnant women in Jimma town. This finding was higher than the prevalence among the general population reported from Nazareth town, Ethiopia, in which $60 \%$ of the sampled population had evidence of $T$. gondii infection [9]. It was also higher than the seroprevalence reported before two decades on samples collected from different regions of Ethiopia [10].

Similarly, the IgG seroprevalence of $T$. gondii obtained in this study was higher than those reported from Palestine [11], Saudi Arabia [12], Brazil [13], Sudan [14], Morocco [15] and China [3]. In contrast, lower seroprevalence of $T$. gondii was reported in many European countries and the United States of America [2]. This wide variability could be attributed to differences in climatic conditions and personal hygienic practices, feeding habits, socio-economic and literacy status of the study subjects.

On the other hand T. gondii overall prevalence was lower than the prevalence among pregnant women in Ghana, where the seroprevalence was 92.5\% [4]. The observed difference in the rates of infection could be 
Table 2 Factors associated with Toxoplasma gondii infection among the pregnant women $(\mathrm{n}=\mathbf{2 0 1})$ in Jimma town, 2011

\begin{tabular}{|c|c|c|c|c|}
\hline \multirow[t]{2}{*}{ Characteristics } & \multicolumn{2}{|c|}{ Seroprevalence } & \multirow[t]{2}{*}{ COR $(95 \% \mathrm{Cl})$} & \multirow[t]{2}{*}{ AOR $(95 \% \mathrm{Cl})$} \\
\hline & Positive $\mathrm{n}(\%)$ & Negative $\mathrm{n}(\%)$ & & \\
\hline \multicolumn{5}{|c|}{ Educational status } \\
\hline Illiterate & $38(77.5)$ & $11(22.5)$ & $1.7(0.76-3.84)$ & $0.66(0.27-1.60)$ \\
\hline Literate & $130(85.5)$ & $22(14.5)$ & 1 & 1 \\
\hline \multicolumn{5}{|l|}{ Occupation } \\
\hline House wives & $134(82.7)$ & $28(17.3)$ & $0.7(0.25-1.96)$ & $0.67(0.23-1.99)$ \\
\hline Others & $34(87.2)$ & $5(12.8)$ & 1 & 1 \\
\hline \multicolumn{5}{|c|}{ Age group (years) } \\
\hline $15-19$ & $16(64.0)$ & $9(36.0)$ & 1 & 1 \\
\hline $20-24$ & $81(83.5)$ & $16(16.5)$ & $2.8(1.07-7.56)^{*}$ & $3.18(1.08-9.34)^{*}$ \\
\hline $25-29$ & $55(88.7)$ & $7(11.3)$ & $4.4(1.42-13.73)^{*}$ & $4.95(1.41-17.38)^{*}$ \\
\hline $30-35$ & $16(94.1)$ & $1(5.9)$ & $9.0(1.02-79.54)^{*}$ & $13.98(1.42-137.92)^{*}$ \\
\hline \multicolumn{5}{|c|}{ Presence of cats } \\
\hline Yes & $56(94.9)$ & $3(5.1)$ & $5.0(1.46-17.10)^{*}$ & $5.82(1.61-20.99)^{*}$ \\
\hline No & $112(75.6)$ & $30(24.4)$ & 1 & 1 \\
\hline \multicolumn{5}{|c|}{ Contact with soil } \\
\hline Yes & $121(81.8)$ & $27(18.2)$ & $0.57(0.22-1.47)$ & $0.63(0.23-1.74)$ \\
\hline No & $47(88.7)$ & $6(11.3)$ & 1 & 1 \\
\hline \multicolumn{5}{|c|}{ Raw meat eating habit } \\
\hline Yes & $87(82.9)$ & $18(17.1)$ & $0.89(0.42-1.89)$ & $0.73(0.31-1.72)$ \\
\hline No & $81(84.4)$ & $15(15.6)$ & 1 & 1 \\
\hline \multicolumn{5}{|c|}{ Source of drinking water } \\
\hline Well & $20(80)$ & $5(20)$ & $0.75(0.26-2.18)$ & $1.22(0.36-4.15)$ \\
\hline Pipe & $148(84.1)$ & $28(15.9)$ & 1 & 1 \\
\hline
\end{tabular}

*Statistically significant at $\mathrm{P}<0.05, \mathrm{COR}=$ Crude Odds Ratio, $\mathrm{AOR}=$ Adjusted Odds Ratio, $\mathrm{Cl}=$ Confidence Interval.

due to variation in age distribution and antibody profiles of the study populations.

In the current study, increase in seropositivity of anti$T$. gondii antibody was observed as age increases, which is in agreement with other previous similar studies $[11,16]$. This could be explained by the fact that older women are more likely to have been exposed to any one of the risk factors than younger women as a result of longer exposure time.

Contact with domestic cats is often mentioned as a risk factor, however, there are also contradicting reports. Our findings showed significant association between T. gondii infection and presence of domestic cats at home, which was one of the predictors for $T$. gondii infection in this study. This finding corroborates with studies reported from France [17] and Taiwan [18]. In contrast, some studies reported absence of association between Toxoplasma infection and presence of domestic cats in the household $[11,19,20]$. The way the cats' litter box is cleaned rather than the simple presence of cats could account for exposure of individuals to the parasite.
Moreover, the prevalence of the parasite among the domestic cats may depend on the type of cats (stray vs pet cats) in different countries, in that stray cats were reported to be more exposed to the parasite as compared to pet cats [21]. In the present study area stray cats were more common and it was expected that the prevalence would be higher.

Contaminated drinking water is also a potential source of T. gondii infection [22]. A study done in Nigeria had also reported higher seroprevalence rate among pregnant women drinking well water compared to those using packed water [20]. Though, in our study, $12.4 \%$ of the study participants reported to use water from well for drinking when pipe water is interrupted or as their sole source of drinking water there was no association between source of water for drinking and Toxoplasma infection.

In the present study, it was observed that 105 (52.2\%) of the pregnant women reported to eat raw meat but showed no significant association with Toxoplasma infection, which is consistent with studies from Turkey 
[19] and Palestine [11]. However, other studies by Elnahas et al. [14] and Ghoneim et al. [23] reported an association of raw meat consumption with Toxoplasma infection. This variation could be due to differences in the prevalence of the parasite in the animals in those countries as well as the type of animals consumed. In a seroepidemiological survey of toxoplasmosis conducted before two decades among domestic animals in Ethiopia, it was reported that $22.9 \%$ the sheep, $11.6 \%$ of the goats and $6.6 \%$ of the cattle examined were seropositive [24]. In Jimma town, it is more likely that raw beef is consumed more often than raw meat of goats or sheep. This indicates that raw beef may not be the major route for the transmission of the parasite in the area. However, vertical transmission may contribute for the high seroprevalence of the parasite as it was reported in a previous study [25].

\section{Conclusions}

Seroprevalence of $T$. gondii antibodies was high among pregnant women and the prevalence showed a corresponding increase as the age of the pregnant women increases. Presence of domestic cats at homes of the pregnant women was identified to be main factor for T. gondii infection. Therefore, awareness creation on the modes of transmission and prevention of $T$. gondii should be made to women of child bearing age in general and pregnant women in particular during their antenatal care follow up. Moreover, there is need to control urban stray cat population to reduce the risk of zoonotic transmission of the parasite.

\section{Additional file}

Additional file 1: (A) Questionnaire developed to assess sociodemographic characteristics of study participants. (B). Questionnaire developed to assess risk factors associated with Toxoplasma infection.

\section{Competing interests}

We declare that we do not have any conflict of interests.

\section{Authors' contributions}

EZ conceived the study, participated in the study design, data analysis and drafted the manuscript. SA, TB, AS coordinated specimen collection and laboratory work, participated in data analysis. AZ participated in the design, supervised data collection and participated in data analysis and DY critically reviewed the manuscript. All authors read and approved the final manuscript.

\section{Acknowledgments}

We would like to thank Jimma University for financial and logistic support. We also thank Jimma Zone Health Bureau and Urban Health Extension Workers for their co-operation during specimen collection. We are also grateful to the study participants.

\section{Author details}

'Department of Medical Laboratory Sciences and Pathology, College of Public Health and Medical Sciences, Jimma University, Jimma, Ethiopia. ${ }^{2}$ Department of Biology, College of Natural Sciences, Jimma University,
Jimma, Ethiopia. ${ }^{3}$ Program of Medical Laboratory Science, Department of Medical Sciences, College of Medical and Health Sciences, Wollega University, Nekemte, Ethiopia.

Received: 21 June 2012 Accepted: 3 December 2012

Published: 5 December 2012

\section{References}

1. Dubey JP: Toxoplasmosis of Animals and Humans. Beltseville: CRC Press; 2010.

2. Pappas G, Roussos N, Falagas ME: Toxoplasmosis snapshots: global status of Toxoplasma gondii seroprevalence and implications for pregnancy and congenital toxoplasmosis. Int J Parasitol 2009, 39:1385-1394.

3. Gao XJ, Zhao ZJ, He ZH, Wang T, Yang TB, Chen XG, Shen JL, Wang Y, Lv FL, Hide G, Lun ZR: Toxoplasma gondii infection in pregnant women in China. Parasitology 2012, 139:139-147.

4. Ayi I, Edu A, Apea-Kubi K, Boamah D, Bosompem K, Edoh D: Seroepidemiology of toxoplasmosis amongst pregnant women in the greater Accra region of Ghana. Gh Med J 2009, 43:107-114.

5. Nowakowska D, Stray-Pedersen B, Spiewak E, Sobala W, Małafiej E, Wilczyński J: Prevalence and estimated incidence of Toxoplasma infection among pregnant women in Poland: a decreasing trend in the younger population. Clin Microbiol Infect 2006, 12:913-917.

6. Al-Hamdani M, Mahdi N: Toxoplasmosis among women with habitual abortion. EMHJ 1997, 3:310-315.

7. Dunn D, Wallon M, Peyron F, Petersen E, Peckham C, Gillbert R: Mother-to-child transmission of toxoplasmosis: risk estimates for clinical counseling. Lancet 1999, 353:1829-1833.

8. Central Statistical Agency (Federal Democratic Republic of Ethiopia): The 2007 population and housing census of Ethiopia, result for Oromia region. Addis Ababa, Ethiopia: Central Statistical Agency; 2010.

9. Negash T, Tilahun G, Medhin G: Seroprevalence of Toxoplasma gondii in Nazareth town, Ethiopia. East Afr J Public Health 2008, 5:211-214.

10. Guebre-Xabier M, Nurilign A, Gebre-Hiwot A, Hailu A, Sissay Y, Getachew E, Frommel D: Sero-epidemiological survey of Toxoplasma gondii infection in Ethiopia. Ethiop Med J 1993, 31:201-208.

11. Nijem K, Al-Amleh S: Seroprevalence and associated risk factors of toxoplasmosis in pregnant women in Hebron district, Palestine. East Mediterr Health J 2009, 15:1279-1284.

12. Mohammad HI, Amin TT, Balaha MH, Moghannum MS: Toxoplasmosis among the pregnant women attending a Saudi maternity hospital: seroprevalence and possible risk factors. Ann Trop Med Parasitol 2010, 104:493-504.

13. Vaz R, Thomaz-Soccol V, Sumikawa E, Guimarães A: Serological prevalence of Toxoplasma gondii antibodies in pregnant women from southern Brazil. Parasitol Res 2010, 106:661-665.

14. Elnahas A, Gerais AS, Elbashir Ml, Eldien ES, Adam I: Toxoplasmosis in pregnant Sudanese women. Saudi Med J 2003, 24:868-870.

15. El Mansouri B, Rhajaoui M, Sebti F, Amarir F, Laboudi M, Bchitou R, Hamad M, Lyagoubi M: Seroprevalence of toxoplasmosis in pregnant women in Rabat, Morocco. Bull Soc Pathol Exot 2007, 100:289-290.

16. Rosso F, Les J, Agudelo A, Villalobos C, Chaves J, Tunubala G, Messa A, Remington J, Montoya J: Prevalence of infection with Toxoplasma gondii among pregnant women in Cali, Columbia, South America. Am J Trop Med Hyg 2008, 78:504-508.

17. Baril L, Ancelle T, Goulet V, Thulliez P, Tirard-Fleury V, Carme B: Risk factors for Toxoplasma infection in pregnancy: a case-control study in France. Scand J Infect Dis 1999, 31:305-309.

18. Lin YL, Liao YS, Liao LR, Chen FN, Kuo HM, He S: Seroprevalence and sources of Toxoplasma infection among indigenous and immigrant pregnant women in Taiwan. Parasitol Res 2008, 103:67-74.

19. Ertug S, Okyay P, Tukmen M, Yuksel H: Seroprevalence and risk factors for Toxoplasma infection among pregnant women in Aydin province, Turkey. BMC Public Health 2005, 5:66. doi:10.1186/1471-2458-5-66.

20. Ishaku B, Ajogi I, Umoh J, Lawal I, Randawa A: Seroprevalence and risk factors for Toxoplasma gondii infection among antenatal women in Zaria, Nigeria. Res J Medicine \& Med Sci 2009, 4:483-488.

21. Lee SE, Kim JY, Kim YA, Cho SH, Ahn HJ, Woo HM, Lee WJ, Nam HW Prevalence of Toxoplasma gondii infection in stray and household cats in regions of Seoul, Korea. Korean J Parasitol 2010, 48:267-270. 
22. Bowie WR, King AS, Werker DH, Isaac-Renton JL, Bell A, Eng SB, Marion SA: Outbreak of toxoplasmosis associated with municipal drinking water. Lancet 1997, 350:173-177.

23. Ghoneim N, Shalaby S, Hassanain N, Zeedan G, Soliman Y, Abdalhamed A: Detection of genomic Toxoplasma gondii DNA and anti-Toxoplasma antibodies in high risk women and contact animals. Global Veterinaria 2009, 3:395-400

24. Bekele T, Kasali OB: Toxoplasmosis in sheep, goats and cattle in central Ethiopia. Vet Res Commun 1989, 13:371-375.

25. Hide G, Morley EK, Hughes JM, Gerwash O, Elmahaishi MS, Elmahaishi KH, Thomasson D, Wright EA, Williams RH, Murphy RG, Smith JE: Evidence for high levels of vertical transmission in Toxoplasma gondii. Parasitology 2009, 136:1877-1885.

doi:10.1186/1471-2334-12-337

Cite this article as: Zemene et al:: Seroprevalence of Toxoplasma gondii and associated risk factors among pregnant women in Jimma town, Southwestern Ethiopia. BMC Infectious Diseases 2012 12:337.

\section{Submit your next manuscript to BioMed Central and take full advantage of:}

- Convenient online submission

- Thorough peer review

- No space constraints or color figure charges

- Immediate publication on acceptance

- Inclusion in PubMed, CAS, Scopus and Google Scholar

- Research which is freely available for redistribution 